\title{
Educational Practices, Curriculum Design and Implementation at the MLT Diploma Program in Uganda
}

\author{
Christopher B. Mugimu ${ }^{1}$, Wilson Rwandembo Mugisha ${ }^{2}$ \\ ${ }^{1}$ Department Foundations and Curriculum Studies, College of Education and External Studies, \\ Makerere University, Kampala, Uganda \\ ${ }^{2}$ Uganda Institute of Allied Health and Management Science (UIAHMS)-Mulago, Kampala, Uganda \\ Email: cbmugimu@gmail.com, rwandembo@gmail.com
}

Received November $2^{\text {nd }}, 2013$; revised December $2^{\text {nd }}, 2013$; accepted December $9^{\text {th }}, 2013$

\begin{abstract}
Copyright (C) 2013 Christopher B. Mugimu, Wilson Rwandembo Mugisha. This is an open access article distributed under the Creative Commons Attribution License, which permits unrestricted use, distribution, and reproduction in any medium, provided the original work is properly cited. In accordance of the Creative Commons Attribution License all Copyrights (C) 2013 are reserved for SCIRP and the owner of the intellectual property Christopher B. Mugimu, Wilson Rwandembo Mugisha. All Copyright (C) 2013 are guarded by law and by SCIRP as a guardian.
\end{abstract}

Contemporary curriculum design and implementation require the use of appropriate educational practices to enhance positive teaching and learning outcomes. This article discusses the study of educational practices and related curriculum antecedents applied during the design and implementation of the Medical Laboratory Technology (MLT) at Mulago Paramedical Schools in Uganda. This study utilized mixed methods (quantitative and qualitative) in which checklists, document analysis, questionnaires, focus group discussions, and interviews were used to gather data at different compliance levels. The sample comprised of 10 educators, 30 clinical supervisors and 63 students. This study revealed that the MLT diploma curriculum was implemented with a multi-disciplinary focus in order to develop confident and dependable health professionals that could function harmoniously in interdisciplinary collaborative teams. The study also revealed that the curriculum designers and educators complied with important curriculum antecedents in its design and implementation process and it's clear that student-centered approaches were used. Furthermore, practicum training and strategies used oriented students to basic practical clinical skills and competencies. The use of a variety of educational practices during curriculum implementation made the teaching and learning process more friendly and interesting. It was concluded that considerable utilization of appropriate educational practices during curriculum development was critical. This area of curriculum development being extremely dynamic further research is needed to ensure continued relevance of curricula in the medical field.

Keywords: Educational Practices; Learning Theories; Curriculum Design; Curriculum Implementation

\section{Introduction}

Educational practices are critical in the design and implementation processes of a curriculum because it creates enabling environment for teaching and learning. The theoretical orientation of a curriculum developer or educational planner influences the educational practices he or she adapts. Educational practices refer to a variety of activities that get done in the interest of fostering education such as interventions intended to improve education as well as cultural innovations to address a broad range of educational issues either by government or communities. For the purpose of this study, educational practices are those activities done by the different stakeholders of education in order to enhance learning outcomes of students. Educational practices may also include, but not limited to preparing education agenda, curriculum development, teaching and learning activities, as well as policy initiation and implementation. Cotton Kathleen (2000) explains how important educational practices are in boosting students' learning outcomes and recommends that they need to be well integrated in order to effectively help students to internalize the subject contents.
Sullivan (2011) also shows how application of different education practices as well as innovational practices can improve learning outcomes and the understanding of students. As such, Suryadi and Kudwadi (2010) offer characteristics and competences of teachers, organization and structure of educational units, workplace (industry), among others as part of important curriculum antecedents. From this perspective, educational practices are part of the society norms, values and notions. They are therefore part of curriculum antecedents and hence form a foundation for curriculum development and implementation. Mugisha (2011) also contends that cultural societal values underlie any curriculum and are therefore curriculum antecedents. Curriculum antecedents were the occurrences that took place before the curriculum was developed which affected its development and implementation. Biesta (2007: p. 2) argues:

"Educational practices should not be left to the opinion of educators but that work should be based upon research evidence...for a transformation of educational research so that educational practice could be transformed into evidence-based practice. The call for a double transformation of educational 
research and educational practice lies at the very center of evidence-based education."

Biesta rightly indicated that appropriate educational practices should be informed by research. Furthermore, other great philosophers such as Vygotsky, Piaget, Dewey, and Freire suggest that appropriate EPs should be grounded in sound educational theories. Educational practices that are informed by sound educational theories and philosophies should lead to appropriate and relevant curriculum design and implementation to promote effective teaching and learning. The important arising question is: to what extent are the educational practices used at MLT informed by sound educational theories and philosophies?

Conceptual and Theoretical framework

The assumption in this study was that when appropriate educational practices get to be identified and applied, students should easily acquire the desired learning outcomes. This is consistent with established educational learning theories like social learning theories (Rajah; 1993, Feuerstein; 1980, Vygotsky; 1978) in which educators and senior professionals act as sources and motivators of learning. Furthermore, according to the cognitive development learning theories (Dewey; 1967, Piaget; 1936, Piaget; 1957), enhanced interaction of students with the learning environment increases their understanding of subject contents. The humanistic and learner consciousness development theories also assume that if students are given freedom to determine their destiny in learning, they tend to become more conscious of their development in learning (Rogers; 1983, Freire; 973, Freire; 1972). Several other theories such as service-learning cognitive theories (Giles, 1991), Kolb's experiential learning theories (Miettinen; 2000, Kolb \& Fry, 1975) and Lewin's experiential learning (field/change) theory (Atherton; 2013, Lewin; 1951) emphasize that students learn from their own experiences.

We should mention that while this paper does not intend to analyze the educational theories associated with each of the educational practices highlighted, it is, however, important to note that each educational practice has underlying theories connected with it. Given the amount of space available, the paper only gives an overview of some aspects of the underlying theories to emphasize their connection with each of the educational practices.

\section{Literature Review}

Educational practices are characterized by arrangements that are deliberately designed to get desired learning outcomes from an education system. For instance, educational practices may involve the establishment of national and institutional policies that may promote pedagogical innovative models which encourage lifelong learning traits among students (UNESCO 2012). Educational practices should also offer a variety of provisions for creating flexible learning opportunities for students (Houston, McCune and Osborne: 2011). Flexible learning opportunities in terms of ensuring alternative delivery modes used to implement the educational programs, study patterns such as permitting fulltime and part-time students, distance work-based, web-based learning, with flexibility in the study, allowing face-to-face instructions (sessions), providing online support, utilizing virtual learning environments, tutor support systems and friendly/accommodating assessment strategies to meet the needs of the majority of learners. According to Kuh (2008), well selected educational practices should benefit students of diverse backgrounds, which currently have become the common phenomenon in higher educational institutions. Educational practices take many forms, depending on learner characteristics as well as on institutional priorities and contexts.

UNESCO (2012) recommends that good educational practices need to be established in all educational programs. As such, institutional policies should play a significant role to influence educational practices. For example, institutional policy at Mulago Paramedical Schools required the practice of exposing different Allied Health professionals through a multidisciplinary training approach which was mandatory to all its students including MLT students (MPS Core curriculum, 1998). Mugisha (2011), in his study evaluating the application of educational practices during the curriculum implementation of the Medical Laboratory educational programs in Uganda, describes how Mulago Paramedical schools have established an [institutional culture] of ensuring that students from different health professions go through a common basic training together as an effort of fostering inter-professional cooperation and collaboration. We suggest that sound educational practices should be part of the culture of any institution. Mugisha and Mugimu (2011) explain how considering epistemology as a curriculum development practice, led to the successful development and implementation of the MLT diploma curriculum with relevant types of knowledge and knowing required in MLT education and practice.

Mugisha and Mugimu (2013) explain how application of educational theories as a curriculum development practice does not only lead to the development and implementation of a suitable MLT diploma curriculum in Uganda, but promotes and enhances the utilizations of appropriate educational practices to facilitate the teaching and learning processes.

- Anderson and Walberg (1994), Chickering and Gamson (1987), and Duk (2008) also suggest the following theory grounded educational practices: Encouraging contact between students and educators. This agrees with theories of mediated learning whereby knowledgeable individuals act as intermediaries between the knowledge being learnt and the students in the process of learning (Feuerstein, 1980).

- Developing strategies that lead learning through the development of teamwork and cooperation among stakeholders, which is consisted with social cognition theories of Vygotsky (1978)

- Use of participatory active learning approaches. This practice is in line with cognitive; learning theories (Ausubel; 1960, Bruners; 1992) as well as humanistic theories (Rogers, 1983)

- Application of the time on task principle during program implementation, which enables learners to agree with their teachers on the time lines for completing specific assignments. This is an aspect of contractual learning as portrayed in the humanistic learning theories. According to the humanistic theories, students are given freedom to determine the pace of their learning (Rogers; 1983), Anderson and Walberg (1994), and Chickering and Gamson (1987) Ensure that educators use effective communication strategies that convey high expectations and standards to students as a means of making them understand what is expected of them.

- Providing support for personalised learning through the appreciation of diverse talents and learning styles among different students. 
- Learners to work on their own in order to develop confidence. Ensuring that alignment of time on task by focusing on educational goals, professional expectations, institutional focus and learning expectations is practiced. This educational practice is in the context of constructive alignment theories of curriculum development (Errington, 2010; Biggs, 1004; Yorke \& Knight, 2004).

- Use of systematic direct teaching to give the main learning issues, as a practice is suitable for giving students new developments in the subject and introducing new subjects (Amri, Ngatia, \& Mwakilasa, 1993). The practice has its roots in the idealism which asserts that knowledge is permanent and that educators have unquestionable authority to knowledge (Ornstein \& Levine, 1993; Ornstein \& Hunkins, 1988).

- The practice of linking of past learning with the current teaching (advance organiser), as teaching/learning strategies and ensuring that students are given a variety of learning choices and tutoring services are part and parcel of the principles of teaching (Amri, Ngatia, \& Mwakilasa, 1993; Ausubel,1960; Ausubel, 1978).

- Encouraging cooperative learning where students support each other by working in groups on specified tasks. It involves students discussing together, teaching each other and solving problems more effectively as groups as opposed to each individual (Barkley, Cross, \& Major, 2005; Vidakovic \& Martin, 2004; Vidakovic, 1997, Slavin, 1996; Davis, 1993). Sahel, Al-Tawil and Al-Hahithi (2013) found that interactive learning was appreciated by students as a suitable method of learning among students.

- Applying principles of adaptive education using a variety of instructional techniques especially utilizing teaching/learning strategies that may lead to the development of intellectual and practical competencies. This is achieved when students are encouraged to work together in groups, which makes them develop collaborative learning traits, critical inquiry skills, searching for information, writing, and presentation skills. This is consistent with phenomenological learning theories (Gross, 2005; Curzon, 2004; Quinn, 1995; Barnum, 1994; Roth, 1994; Rajah, 1993; Bevis, 1982) where teaching and learning get adjusted to the demands of the prevailing situation and interests of the student. This also is applicable to the humanism (Quinn, 1995; Joseph, 1985; Carter, 1978) and existentialism (Gulino, 1982; Sartre, 1973; Kneller, 1971; Triostontaines, 1971) realms of philosophical interests and experiences of the student. This approach tends to be learner centred.

- Integrated learning across disciplines. It involves forming learning communities where learners of different programs or courses and their teachers form study groups that address multidisciplinary issues. Such a practice makes students look at education as being beyond the classroom. This makes students appreciate the idea of learning communities as an educational goal. This is consistent with the reconstructions' (Lovat \& Smith, 2003; Freire, 1972), holism (Johnson, 1990; Bevis, 1982; Carter, 1978) and humanism (Quinn, 1995; Joseph, 1985; Carter, 1978) philosophies as well as phenomenological learning theories (Gross, 2005; Curzon, 2004; Quinn, 1995; Barnum, 1994; Roth, 1994; Rajah, 1993; Bevis, 1982).

- Making students work together as colleagues. Collaborative assignments and joint projects to students makes them learn to work and solve problems in the context of teamwork (Giles, 2010; Clark, 2006). They learn from each other's experience and eventually gain their own.

Furthermore, meaningful research experience to students as a practice makes learners work to get solutions for important questions. This can be given as a research project assignment to individual learners. The project may be on an identified area of the program or it may integrate different aspects of the program. This agrees with realism realm of philosophy where facts need to be proved using scientific means (Ornstein \& Hunkins, 1988; Bigge, 1982). This is also consistent with the cognition theories of Ausubel (1978) and Bruner (1992) where it is emphasised that students learn well when they are active participants in learning and creation of knowledge. The practice makes them learn to make empirical observations, make analyses and deductions and as a result derive new meanings. This is consistent with the theories of knowing. The theories of knowing assert that when students add new knowledge to old knowledge they acquire new meanings (Wink, 2010; Spector, 1993). It also develops the spirit of being appreciated when they do big things. It is a modelling for making important findings. It prepares students to appreciate and accept changes. The practice is consistent with the pragmatism realm of philosophy where reality is dependent on experience of individuals (Ornstein \& Hunkins, 1988; Zais, 1976). Involvement in experimental learning, as an aspect of experiential learning as a practice makes students appreciate work place challenges. This can be provided in form of internships or practicum attachments. This is consistent with social cognition learning theories where students learn from senior professionals in the places of work (Vygotsky, 1978) as well as mediated learning theories where those who know act as intermediaries between the knowledge and the student in the process of students learning (Feuerstein, 1980).

National policies guide curriculum development and implementation and likewise, guide educational practices. In Uganda there is a practice of students contributing to the budget of running training institution. This practice is guided by a policy in Higher education which allows institutions to collect funds from trainees and use it for the day-to-day operations (The Uganda Higher Education cost, 2003); Uganda Higher Education Policy, 2004). This practice has made it possible for institutions to easily implement their educational programs with resources generated locally at the institution. In the health sector, guidelines for provision of health care have been documented in the Health Policy (1999), the Health Sector Strategic Plan (2005/6-2010 and 2010/11-2015/16) as well as in the Minimum Health Care Package (2000). This strategic plan has led to designing and implementing the Medical Laboratory Technology curriculum in a manner of mimicking the work environment of the graduate of the MLT training. The attempt to mimic the work environment is consistent with the evidence-based education that is widely used in the field of medicine. And so the Health Sciences Education requires to have specific educational practices applied in order to make it effective and relevant. Indeed, the application of androgogical approaches especially those that promote self-directed learning such as constructivism approach in teaching and learning, reflective practices and helping students to convert theory into practice and development of self-efficacy, are some of the practices that are recommended to be integrated in medical education/health sciences education (Kaufman, 2003).

Flexibility approaches in curriculum implementation are also 
some of the educational practices that could make individual learners to have increased participation and access to teaching and learning by removing restrictions from the way knowledge is accessed. In this context, restrictions to knowledge access could be such as using conventional teaching methods, textbooks, etc. This is active learning and leads to the development of lifelong learning skills. Houston Macune and Osboner (2011), Morgan-Klein and Osborne (2007), Sankey and Osborne (2006) and Percy and Ramsden (1980) explain that application of flexibility in learning tends to benefit students in breaking the bureaucratic mechanisms that usually exist in acquisition of knowledge and accreditation of the past experiences of students. Accreditation of past experience of students involves thinking and reflecting on the experience by both the students and the curriculum implementers. This is a reflective practice in curriculum implementation. Reflection on the past experience by the students leads them to understand the previously learnt knowledge in numerous new ways. According to Kim (2011), learning should also involve unlearning. As such, reflective practice also involves unlearning some aspects of the past experiences in order for the student to accept and appreciate the new knowledge. On the part of the student, this is also an aspect of active learning. Kuh (2008) reveals that if utilizetion of active learning practices is not systematically applied in various institutions, this could undermine students' learning.

The use of internet i.e. e-learning is another educational practice (Luke, Solomon, Baptiste, Orchard, Rukholm, \& Carter, 2009) recommended by Luke, Salomon et al. for enhancing inter-professional Health Sciences Education. These authors contend that a core curriculum for various Health Professionals can be best transmitted through e-learning/web-based learning.

Development of inter-professional education that leads to the emergence of inter-professional practice is yet another Educational Practice that is used in training of Health Professionals. This is a very important practice because it gives a common inter professional agenda to the various health cadres involved in various related inter-professional practices. For example, this practice is characterised as having common subjects together, holding inter-professional projects, and clinical attachment.

Jelesiewicz (2011) discusses educational practices applied in the teaching of Health Practices applied in the teaching of Health Sciences at Temple University in the United States of America (USA). These educational practices include, but not limited to, a) identifying and solving common issues of different disciplines as a team of educators from the concerned disciplines, b) emphasizing clinical teaching, c) team teaching, and d) practicing the taught knowledge simultaneously in a manner that takes interests of patients and trainees. Furthermore, the integration of professionalism in the teaching and assessment of trainees is vital and needs to be applied. Adams (2009) also describes how educationists in laboratory-based education in the United Kingdom agreed in a conference that using enquiry based approach in laboratory teaching allows trainees to observe phenomena, test hypotheses, design experimental strategies and reach conclusions as a result of recording and making critical analyses of experimental results. It was further noted that laboratory teaching and learning needed to be planned and executed in an exciting and realistic context.

- All the mentioned educational practices and curriculum antecedents are crucial especially in managing the challenge of examination tensions that should occur when students are ineffectively taught theory and practical skills.

\section{Methodology}

This study utilized mixed methods in which we used checklists and document analysis as instruments to gather data at different compliance levels during the design and implementation of the MLT curriculum. The checklists were developed drawing on the information extracted from the literature review and policy documents guidelines. The checklists also contained the standard descriptions of the expected status for an ideal medical education program. The checklists were also used during the focus group discussions.

\section{Purposive Sampling}

Technique was used to select educators and clinical supervisors who participated in the study because they were few and highly specialised in their subject disciplines. The research sample comprised of 10 educators and 30 clinical supervisors. The educators were both part-and full-time tutors at the School of MLT, at Mulago Paramedical Schools. The supervisors were employees of the Ministry of Health based at Mulago Hospital, and others were employed by Makerere University at The College of Health Sciences. Supervisors and educators were included because they carried out the supervision of MLT students during the practicum attachments. This implies that the sample constituted $100 \%$ of the educators and supervisors. A sample of 63 students in SMLT were selected based on eligibility. The eligibility criteria for inclusion in the study were as follows: the student should have completed one year of study at the institution and was not yet in the specialised part of the program.

\section{Documents}

Documents were selected according to their relevance to the study. The documents selected included the MLT curriculum documents, the Health Sector Strategic Plan (HSSP) 2005/062009/10, 2005; Poverty Eradication Action Plan (PEAP), 2005; Curriculum of Diploma in Medical Laboratory Sciences, 2006; Guidelines for Private Practice of Nurses and Allied Health Professionals, 2002; The Guidelines for Medical Laboratory Practice, 2002; The health policy, 1999; The education White Paper, 1998); International directory of Biomedical Laboratory Sciences Education (Karlton \& Turner, 1998); The Uganda Constitution, 1995; school time tables, school administration files, office assessment results records, students' note books and practical assessment record books, educators' notes and schedules and the United Nations Organisation (UNO) agencies publications. All these documents were critically analysed to understand the situation. Situational analysis also involved investigating whether the curriculum antecedents were considered during curriculum development. This was done by analysing the relevant documents which represented the different curriculum contexts using check lists and observational schedules.

\section{Data Collection}

Self-reporting questionnaires were also administered to different respondents (learners, educators and supervisors). These 
instruments were used to generate data that enabled us to compare the curriculum content and implementation strategies with requirements of the various curriculum contexts. The questionnaires also investigated the assessment practices, in particular, to establish whether there was evidence of institutional support to the teaching and learning processes, in particular, the congruence between the official and curriculum in action and students' attainment of learning outcomes. Furthermore, the study also investigated how educators applied various educational practices in their teaching and how they coped with the curriculum schedules. Focus group discussions were also conducted using semi-structured interviews among the students, educators and supervisors. A check list of issues covered during the focus group interviews was developed drawing on key ideas arising from the situational analysis, document analysis and the surveys. The aim of the focused group discussions was to get verbatim responses as well as obtain clarifications and explanations of the written responses arising from the situational analysis and survey.

\section{Data Analysis}

Data were organised in tabular and chart forms to facilitate the establishment of the relationships that existed in the data. The quantitative data was analysed using a statistical package (SPSS 11.0). The quantitative data analysis generated descriptive statistics presented in tables and charts. It also involved calculation of correlation coefficients and statistical significance.

Drawing on the Ground Theory principles, the analysis of qualitative data involved the organisation of responses from respondents into common themes and sub-themes. This involved studying responses presented in the narratives as contained in each of the questionnaires, focus group discussions and a careful analysis of all curriculum policy documents.

\section{Results}

We probed to find out what educational practices were being used by educators to implement the MLT diploma curriculum program. Findings revealed that the MLT diploma curriculum was implemented at MPS which is a multi-disciplinary institution. Thus, MPS developed confident and dependable health professionals, enabling them to function harmoniously in an interdisciplinary team. It is also the only Allied Health Training Institution preparing different cadres of Allied Health Professionals. The learners were oriented to appreciate the interdependency of different health cadres and to uphold ethical principles underlying their professional practice while making clinical decisions.

Mulago Paramedical Schools used a core multidisciplinary curriculum in order to make all the students of the diverse backgrounds have a uniform standard in basic sciences. Students of the MLT diploma program followed a multidisciplinary core. Curriculum comprised of basic sciences such as anatomy, physiology, microbiology and psychology during their first semester of the first year of study (MPS Core Curriculum, 1998). Educators at MPS used student-centred approaches during curriculum implementation.

This made students achieve the desired learning outcomes as evidenced by their performance in their examinations in Table 1. Table 1 shows the performance of learners at the end of each year between 2000 and 2007. From this table it is clear that performance of learners in the examinations was relatively good, which is a reflection that the appropriate educational practices are being used in the MLT program.

\section{Curriculum Designers Complied with Curriculum Antecedents}

Investigations were done to establish whether the design of the MLT curriculum was in accordance with its antecedents. The investigations were done by use of checklists containing statements extracted from the curriculum depicting characteristics of various antecedents of the curriculum indicated in the table below. The study results established that the curriculum design process was compliant with the curriculum antecedents as indicated in Table 2.

The results in the Table 2 show that most of the items tested had compliance at $100 \%$. The items which did not have $100 \%$ compliance were also very high i.e. more than $82 \%$. It is not surprising that during the focus group discussion with the clinical supervisors, it was revealed that, the supervisors confidently expressed satisfaction with their contribution to the implementation of the curriculum and explained that they expected compliance to be at $100 \%$ all through (Supervisor 1).

They explained that where the performance fell short of their expectations, it was because they did not know what to be expected. However, they blamed it to the inadequate communication among the educators.

- The institution (MPS) has a practice of regular Assessment of Progressive Achievement of Learning Outcomes;

- Progressive achievement of learning outcomes was investigated analysing responses of students, educators and clinical supervisors. What comes out clearly is that responses depicted the $100 \%$ administrative support given towards the practice of progressive assessment of students' learning outcomes as presented in Table 3. From the results in Table 3 , it is clear that the curriculum implementation process carried out progressive assessment of students learning outcomes at the rate of $90 \%$.

Table 3 shows that curriculum implementation had administrative support towards the assessment process to ensure that

Table 1.

Shows examination results of MLT students by year.

\begin{tabular}{lcccccccc}
\hline \multicolumn{1}{c}{ Year } & 2000 & 2001 & 2002 & 2003 & 2004 & 2005 & 2006 & 2007 \\
\hline Number of candidate & 36 & 41 & 43 & 50 & 45 & 18 & 63 & 77 \\
Number passed & 32 & 31 & 27 & 40 & 37 & 12 & 44 & 48 \\
\% pass & 89 & 76 & 63 & 80 & 82 & 67 & 70 & 62 \\
& Average pass rate per year $=\mathbf{7 4 \%}$ & & & & & & \\
\hline
\end{tabular}


Table 2.

Shows how the curriculum design compiled with the curriculum antecedents.

\begin{tabular}{|c|c|c|c|c|c|c|}
\hline Antecedents & $\begin{array}{c}\text { No of } \\
\text { statements per item }\end{array}$ & $\begin{array}{c}\text { Full } \\
\text { Compliance \% }\end{array}$ & $\begin{array}{c}\text { Partially } \\
\text { Comply \% }\end{array}$ & $\begin{array}{c}\text { Total } \\
\text { compliance \% }\end{array}$ & $\begin{array}{c}\text { Does not } \\
\text { comply \% }\end{array}$ & Total \% \\
\hline $\begin{array}{l}\text { Following pricipal leading } \\
\text { to career path }\end{array}$ & 20 & 85 & 5 & 90 & 10 & 100 \\
\hline $\begin{array}{l}\text { Following curriculum } \\
\text { design principles }\end{array}$ & 7 & 86 & 14 & 100 & 0 & 100 \\
\hline $\begin{array}{l}\text { Using outcomes that lead } \\
\text { to skills development }\end{array}$ & 25 & 80 & 20 & 100 & 0 & 100 \\
\hline Curriculum content relevance & 34 & 76 & 24 & 100 & 0 & 100 \\
\hline $\begin{array}{l}\text { Applying established } \\
\text { educational strategies. }\end{array}$ & 11 & 73 & 9 & 82 & 18 & 100 \\
\hline $\begin{array}{l}\text { Using existing facilities } \\
\text { for clinical exposure }\end{array}$ & 12 & 100 & 0 & 100 & 0 & 100 \\
\hline $\begin{array}{l}\text { Following curriculum administration } \\
\text { and assessment recommendations }\end{array}$ & 36 & 9 & 86 & 95 & 5 & 100 \\
\hline
\end{tabular}

Table 3.

Shows percentage compliance of the administration to curriculum recommendations.

\begin{tabular}{|c|c|c|c|c|c|c|c|c|c|c|}
\hline \multirow[t]{2}{*}{ Item } & \multicolumn{2}{|l|}{ Complies } & \multicolumn{2}{|c|}{ Partially complies } & \multicolumn{2}{|c|}{ Total Compliance } & \multicolumn{2}{|c|}{ Does not comply } & \multicolumn{2}{|c|}{ Total } \\
\hline & $\mathrm{N}$ & $\%$ & $\mathrm{~N}$ & $\%$ & $\mathrm{~N}$ & $\%$ & $\mathrm{~N}$ & $\%$ & $\mathrm{~N}$ & $\%$ \\
\hline Assessment Process & 12 & 85 & 1 & 5 & 13 & 90 & 1 & 10 & 14 & 100 \\
\hline Assessment Administrative support & 7 & 86 & 1 & 14 & 8 & 100 & 0 & 0 & 8 & 100 \\
\hline $\mathrm{n}=$ Number of statement & & & & & & & & & & \\
\hline
\end{tabular}

this process followed key curriculum recommendations. This is an important educational practice for an educational institution because assessment of learning is the only sure way of measureing whether learning is taking place or not.

For instance, during the focus group discussion some of the educators and clinical supervisors indicated that the time of assessment and the nature of assessment were well known to them. The curriculum document is clear of the nature and time of assessment in the implementation schedule (Educator 1). It is clear that at the end of each semester there would be an assessment and the content to be assessed would be in alignment with the procedures students performed during that semester (Supervisor 2). Both educators and supervisors were in agreement that the guide lines were strictly followed during the implementation of the curriculum. This showed that there was collaborative understanding and interest among the different stakeholders of the MLT curriculum and its implementation.

Students' Views about application of student-centred approaches during Curriculum Implementation further reflected on students' responses and enquiry into their views concerning teaching and learning strategies, learning experiences, content presentation, learning environment/climate and assessment of their learning outcomes during the curriculum implementation at the MLT, the findings clearly show that the teaching-learning approaches applied were student-centred (SCA) i.e. ranging between $76 \%$ and $93 \%$. For instance, during the focus group discussion with students revealed that: Discussing academic issues with our peers is pleasurable, makes one compare oneself with colleagues and increases understanding. Carrying out projects on our own with moderation of educators, makes us develop confidence (Student 1). This quote indicates that students appreciated their participation and engagement with peers during the teaching and learning process. These views also show that there was positive development of lifelong learning habits among the students.

Teaching-Learning Approaches: Sixty three students' respondents returned the questionnaires. The results in Tables 4 and 5 reflect students' views with respect to the implementation of the teaching and learning strategies.

Table 4 shows that $69 \%$ of students felt that the theoretical contents offered at the Medical Laboratory Technology (MLT) were generally presented drawing on student-centred approaches. $59 \%$ of students felt that student-centred approaches were also utilized during practical teaching as well as practicum attachment. Although there were some aspects of teach er-centred tendencies, however, student-centred approaches predominated. This is reflected in the following quotes:

1) When students stay on the MLT program for at least one year they become confident and do most of the learning amongst each other and individually on their own (Educator1)

2) When supervising senior students of the MLT program, one only gives minimum guidance because they appear to be confident and to perform most of the procedures on their own as well as consulting amongst each other (Supervisor 3). This explains the low rating of the teacher-centred approach in Table 3.

This implies that both educators and supervisors applied student-centred educational practices. It also implies that the MLT program is practical-oriented, promoted critical thinking, and problem-solving skills. Indeed, learning was enhanced by doing so and through active individual participation of students.

Table 5 shows that educators' application of teacher-centred strategies especially during the teaching of theoretical knowledge was $86 \%$, practical $75 \%$ and practicum $73 \%$ respectively. From these results, it is clear that even in practical programs such as the MLT there was some application of teacher-centred 
Table 4.

Shows Students' Perception about the Application of SCA by Educators.

\begin{tabular}{|c|c|c|c|c|c|c|c|c|c|c|}
\hline \multirow[b]{2}{*}{ SCA Learning experiences } & \multicolumn{2}{|c|}{ Strongly agree } & \multicolumn{2}{|c|}{ Agree } & \multicolumn{2}{|c|}{ Total agree } & \multicolumn{2}{|c|}{ Strongly disagree } & \multicolumn{2}{|c|}{ Total disagree } \\
\hline & $\mathbf{n}$ & $\%$ & $\mathbf{n}$ & $\%$ & $\mathbf{n}$ & $\%$ & $\mathbf{n}$ & $\%$ & $\mathbf{n}$ & $\%$ \\
\hline In theoretical learning & 25 & 40 & 18 & 29 & 43 & 69 & 20 & 31 & 20 & 31 \\
\hline In Practical learning & 13 & 20 & 25 & 39 & 37 & 59 & 41 & 26 & 26 & 41 \\
\hline In Practicum & 13 & 20 & 25 & 39 & 37 & 59 & 41 & 26 & 26 & 41 \\
\hline $\mathrm{n}=$ Number of learners & & & & & & & & & & \\
\hline
\end{tabular}

Table 5.

Shows students' perception of the application of TCA practices by educators.

\begin{tabular}{|c|c|c|c|c|c|c|c|c|c|c|}
\hline & Always & & Often & & Seldom & & & & Never & \\
\hline TCA & $\mathrm{n}$ & $\%$ & $\mathrm{n}$ & $\%$ & $\mathrm{n}$ & $\%$ & $\mathrm{n}$ & $\%$ & $\mathrm{n}$ & $\%$ \\
\hline In theoretical sessions & 20 & 32 & 20 & 32 & 14 & 22 & 54 & 86 & 9 & 14 \\
\hline In practical sessions & 18 & 29 & 13 & 21 & 16 & 25 & 47 & 75 & 16 & 25 \\
\hline In Practical attachment & 16 & 25 & 14 & 23 & 16 & 25 & 46 & 73 & 17 & 27 \\
\hline $\mathrm{n}=$ number of students & & & & & & & & & & \\
\hline
\end{tabular}

approaches especially in the teaching of underlying principles and theories on which various experiments are based. Teachercentred approaches were also used when educators carried out demonstrations of procedure, especially during the time of introducing students to basic laboratory procedures.

Furthermore, during focused group discussions, some of the educators explained how they usually take a lot of time in explaining principles and cultures of the medical profession to the newcomers (freshmen) as a way of orienting them into the medical related training/profession. This is usually done in form of direct lecturing to the students. For instance, one of the educators indicated that "It takes a lot of time explaining new concepts and demonstrating laboratory procedure especially in the first year of the program" (educator 13). The clinical supervisors elaborated on how students take time to get used to routines of the clinical laboratories. They said this made them take some time inducting students.

Learning Experiences were more of student-centred than teacher-centred. The results of the investigations into the common learning experiences encountered by students during curriculum implementation indicated that the experiences in theoretical subject contents was predominantly student-centred $(69 \%)$ and in practical teaching and practicum attachment the tendency was at $59 \%$. These tendencies provided the learning experiences during curriculum implementation as reflected in Tables 6. As earlier observed, although there were tendencies of TCA during curriculum implementation, the SCA dominated.

MLT being a 'hands on program', supervisors during the focused group discussion narrated how students needed to gradually gain confidence and to work on their own in clinical sites (clinic, hospital, and medical laboratory) during practicum attachments.

The analysis of the responses in Table 6 seems to be complementary to the explanations given in Table 4 . At the beginning of the program, educators tend to use more of teachercentred than student-centred approaches while towards the end of the program, the approaches get predominantly studentcentred. This is important because students at this point in their education cycle need to gather a lot of information on their own about the new field they will have joined.

\section{Discussions}

From the findings of the study it was also revealed that the curriculum design phase at the MLT extensively considered relevant curriculum development principles. For example, curriculum designers identified important curriculum antecedents of the MLT program. It was therefore not surprising that the professional context had been fulfilled.

The curriculum enhanced outcomes that led to the development of appropriate and relevant skills required for the functional practice of MLT.

The findings also showed that the curriculum document identified the different levels of existing Health facilities as described in the Health policy (The Health Policy, 1999). This was found to have been considered during the planning of attachment in the practicum training sites where students carried out their practical clinical orientation. There were also documented strategies for exposure of students in the practicum sites.

The strategies emphasised the use of senior professionals as supervisors during clinical placement of students. In this context, the educational practice of having teaching as a shared responsibility between educators and clinicians was upheld. This enabled students to acquire relevant professional skills. This was mainly reinforced by utilizing curriculum implementtation strategies that emphasized both clinical and team teaching.

The exposure to clinical practice was mandatory for the fulfilment of the professional registration of graduates as described in the Allied Health Statute (Allied Health Statute; 1996). The MLT curriculum therefore integrated educational practices that enabled students/trainees to be professionally qualified. This educational practice ensured that the MLT curriculum development process followed relevant curriculum design principles and aligned the curriculum to its professional context. 
Table 6.

Shows application of TCA during the teaching/learning process.

\begin{tabular}{|c|c|c|c|c|c|c|c|c|c|c|c|c|}
\hline \multirow[b]{2}{*}{ Learning Experiences TCA } & \multicolumn{2}{|c|}{ Strongly Agree } & \multicolumn{2}{|c|}{ Agree } & \multicolumn{2}{|c|}{ Total agree } & \multicolumn{2}{|c|}{ Disagree } & \multicolumn{2}{|c|}{ Strongly disagree } & \multicolumn{2}{|c|}{ Total disagree } \\
\hline & $\mathrm{n}$ & $\%$ & $\mathrm{n}$ & $\%$ & $\mathrm{n}$ & $\%$ & $\mathrm{n}$ & $\%$ & $\mathrm{n}$ & $\%$ & $\mathrm{n}$ & $\%$ \\
\hline In Theoretical learning & 13 & 21 & 20 & 32 & 33 & 53 & 18 & 29 & 9 & 14 & 30 & 47 \\
\hline In practical learning & 13 & 21 & 23 & 36 & 36 & 57 & 9 & 14 & 18 & 29 & 27 & 43 \\
\hline In practicum attachment & 11 & 17 & 23 & 37 & 34 & 54 & 23 & 36 & 6 & 10 & 29 & 46 \\
\hline
\end{tabular}

The results of the study also indicated that various educational practices were applied during the implementation of the curriculum. The implementation process included providing flexible learning opportunities for trainees during individual projects and in all areas where student-centered approaches were applied.

Flexibility approaches in curriculum implementation took care of the diversity of students; thus, encouraged individuals to have increased participation and access to learning thus removing restrictions on the way knowledge was accessed. This approach benefited students as it breaks bureaucratic mechanisms that usually exist in the acquisition of knowledge and accreditation of the past experiences. This is in agreement with other authors (Sankey and Osborne, 2006) who explain that using flexible approaches as a curriculum implementation practice enables individual students to actively participate in the teaching and learning process; given that it removes restrictions on the part of students in the process of accessing knowledge. This is often referred to as active learning and may lead to the development of lifelong learning skills. This is in agreement with the views of Houston Macune and Osboner (2011), Morgan-Klein and Osborne (2007), Sankey and Osborne (2006) and Percy and Ramsden (1980) explain that application of flexibility in learning benefits students in breaking the bureaucratic mechanisms that usually exist in acquisition of knowledge and accreditation of the past experiences.

The curriculum implementation process encouraged group and individual studies as strategies to promote the development of lifelong learning skills among students. Furthermore, the use of a variety of educational practices during curriculum implementation made the teaching and learning process more friendly and interesting. As such, many students experienced a good masterly of the subject content as indicated in the examinations results in Table 1. Responses from the students also showed that they were satisfied with the assessment schedules as well as assessment strategies which subsequently reduced the tensions among students which usually accrue from examinations.

Indeed, the flexible approaches used during the MLT curriculum implementation were overwhelmingly appreciated by the students.

For instance, the assessment strategies that encouraged the use of group discussions were found to be flexible and allowed students to take responsibility of their own learning as opposed to educators dominating the teaching/learning process; as it gives students the opportunity to teach each other as well as to communicate their individual ideas to external audience. Through such, they also gain experience in communicating with peers. They also developed confidence in their intellectual capacities as well as get opportunity to compare themselves with their colleagues thus developing self-acceptance and selfconfidence. Using small group teaching/discussion approaches as an educational practice also helped teachers to deal with large classes in terms of enhancing students' opportunities to discuss content in small groups more effectively which would be difficult in the large class.

This study further revealed that there was an institutional policy for a core curriculum, that enabled students from different disciplines to study a uniform curriculum in basic sciences, research, information technology and management. The approach involved having students from these different disciplines study together, getting collaborative assignments and joint projects. They were also assessed together which made them look at each other as members of the same calling. This was intended to enable them to learn to work and solve problems as team members. This approach to health sciences education is in line with the practice at Temple University in the USA (Jelesiewicz, 2011). This approach in health training has also been encouraged and recommended by scholars as ideal practice for forming learning communities where students of different programs or courses and their teachers form study groups that address multidisciplinary issues. The multidisciplinary core curriculum approach in health sciences education helped students look at classroom teaching and learning as a professional practice aimed at addressing community-oriented services rather than simply acquiring knowledge in classrooms per se. This inculcates their desires to value working for and in communities as teams as opposed to individuals or individual professionals. Establishing a culture of this nature is a good example of establishing strategic educational practices. Mugisha (2011) recommends that establishing unique institutional ethos (educational practices) should be a culture of any tertiary institution.

The results of analysis of the curriculum document also showed that the curriculum content had some component of integrated Information communication Technology (ICT). This prepared students to make use of the Internet in facilitating their learning. The use of Internet is an educational practice which involves e-learning. Luke, Solomon, Baptiste, Orchard, Rukholm and Carter (2009) observed that the use of e-learning is an ideal educational practice for enhancing inter-professional Health Sciences Education.

Subsequently, the inter-professional education and e-learning training have both been integrated into the MLT program. Granted the promotion of inter-professional education as an educational practice could enhance understanding, confidence and teams of inter-professional nature. This helps in making individuals belonging to the various professionals work together to solve inter-professional problems (Clark: 2006, Andrews: 2005, Epstein: 1999). This is a very important approach 
for the training of various cadres involved especially in contemporary healthcare delivery services because it gives them an opportunity to follow a common inter-professional agenda. It may also help them to identify common problems and get their solutions. This approach is also in line with educational practices at Temple University where teaching of professionalism has been integrated in the Medical Education curriculum (Jelesiewicz, 2011).

The results of the investigations showed that students were exposed to problem-based learning procedures either on their own or in groups, where they are given assignments and projects that are problem-solving in nature. As such, students were prepared to discover the trends in their learning and future working environments. This approach required them to deeply think about their enquiries into issues related to contemporary healthcare services in order to find out appropriate solutions. Most of the assignments tend to focus on the practical aspects of their clinical profession, with the aim of enhancing the development of practical competencies. In this regard, students were also encouraged to develop research skills such as; taking credit for making appropriate empirical observations, and obtaining important findings. The other attributes of this approach promoted collaborative learning skills, critical inquiry skills, ability to search for information, report writing, and presentation skills.

What comes out clearly from this research is that utilization of appropriate educational practices leads to relevant curriculum design and implementation that in turn contributes to the effective learning experiences reflected in Figure 1. This research has also revealed that considerable utilisation of appropriate educational practices during curriculum development is critical in a sense that it may enhance identification and use of appropriate curriculum antecedents that could consequently influence the relevance of curriculum content. Thus, identification of curriculum antecedents is a very important educational practice in curriculum development. As such, government policies concerning the national disease burden and international trends have been integrated in the MLT curriculum and thus have significantly influenced the MLT curriculum content. These are the real antecedents of this curriculum. This area of curriculum development is extremely dynamic and therefore needs to be studied carefully and exhaustively in order to ensure continued relevance of curricula.

It is also clear that the establishment of institutional ethos and culture may influence the character of trainees, which may extend into their future professional life and practices. This study has revealed that the institutional ethos of MPS focused on multidisciplinary, multi-professional, multi-cultural institution practices and principles. The MLT curriculum was

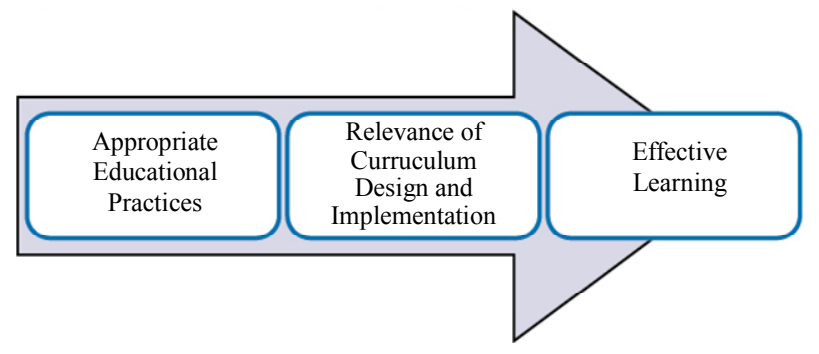

Figure 1.

Shows the curriculum design and Implementation model. therefore developed under a multicultural, multidisciplinary arrangement which was relevant for diversity of backgrounds of its trainees. This arrangement was ideal to meet educational needs of students from different backgrounds. The curriculum was also relevant to the diverse educational standards and cultures of students. It contained also relevant strategies for enhancing multidisciplinary educational experiences. The implementation of the MLT curriculum fitted within this culture. The curriculum was therefore relevant to the institutional context in which it was designed and implemented. As such, what came out clearly from this study is that multidisciplinary education requires good organisation and coordination. This also implies that ideal management models for such institutions and educational programs need to be developed.

Further research is needed in the field of curriculum design and implementation especially in the developing countries. Given that Health Sciences Education is extremely dynamic in terms of the delicate manner/nature in which healthcare services are delivered to the diverse communities. Thus, the training of health professionals demands that it has to utilize a variety of appropriate educational practices to enhance the acquisition of needed professional experiences and competencies of the trainees and graduates. Consequently, the implementation of curricula for Health Sciences Education needs to use educational practices that involve as many stakeholders as possible in order to offer appropriate training environments as an implementation strategy. By doing so, such an approach would address concerns and demands of the different stakeholders. It should also deal with the concerns of educators who implement the curriculum, the students, the institutional settings in which implementation takes place, the clinical sites that give/provide the ideal professional experiences and the communities who will be affected by the implementation of the curriculum. There should also be linkage between the innovators and the users of the innovation. Furthermore, research into these curriculum issues, particularly looking into the best educational practices in curriculum design and implementation of healthcare related programs within the resources constrained contexts, particularly in developing countries is needed. For instance, the integration of training programs in one institution, as an educational practice, could be the way to go, however, this needs to be experimented and its cost benefit analysis for several programs may be necessary. Educational practices that could support and encourage institutions in optimizing the opportunities arise from practices of utilizing economies of scale. Such institutions may also need to develop a culture which models characteristics of its students. Studies of development and management of such institutions need to be done in order to develop bulk of knowledge in this healthcare education. This would add on the knowledge and experience from Temple College already reviewed in this study.

\section{Conclusion}

From the results and discussions in this study, it is clear that proper application of appropriate educational strategies and practices which promote students' interests and positive learning experiences is done at the MLT. The application of flexible strategies was central in the process of curriculum implementation and it positively influenced the teaching/learning process. This study had shown that students not only enjoyed studentcentred approaches being used at the MLT, but also benefited a 
great deal in terms of gaining relevant clinical practical skills. This is reflected by the high performance rates of students. However, it remains to be a huge challenge for educators to ensure that they apply appropriate educational practices. Educational institutions therefore need to put up professional development programs for their educators, to equip them with current emerging trends in educational practices especially in the medical field. This may empower them with the needed competencies to apply appropriate and current educational practices in their work place.

\section{REFERENCES}

Adams, J. D. (2009). Current trends in laboratory class teaching in university bioscience programs. UK Centre for Bioscience, Higher Education Academy, and Faculty of Biological Sciences, University of Leeds.

Anderson, L. W., \& Walberg, H. J. (1994). Time piece: Extending and enhencing learning time. Roston, VA: National Association of Secondary Principles.

Andrews, K. (2005). Evaluating professional development in the knowledge era. Sydney: TAFE NSW ICVET International Centre for VET Teaching and Learning.

Atherton, J. S. (2013) Learning and teaching; experiential learning. $\mathrm{http}: / /$ www.learningandteaching.info/learning/experience.htm

Ausubel, D. P. (1960). The use of advance organizers in the learning and retention of meaningful verbal material. Journal of Educational Psychology, 51, 267-272. http://dx.doi.org/10.1037/h0046669

Ausubel, D. (1978). In defense of advance organizers: A reply to the critics. Review of Educational Research, 48, 251-257. http://dx.doi.org/10.3102/00346543048002251

Barkley, C., Barkley, E. F., Cross, K. P., \& Major, C. H. (2005). Collaborative learning techniques: A handbook for college faculty. San Francisco, CA: Jossey Bass.

Bevis, E. O. (1982). Curriculum building in nursing: A process. St Louis: Mosby.

Biesta, G. (2007). Why "what works" won't work: Evidence-based practice and the democratic deficit in educational research. Education Theory, 57. http://dx.doi.org/10.1111/j.1741-5446.2006.00241.x

Carayannis, E. G., Popescu, D., Sipp, C., \& Stewart, M. (2006). Technological learning for entrepreneurial development (TL4ED) in the knowledge economy (KE): Case studies and lessons learned. Technovation, 26, 419-443. http://dx.doi.org/10.1016/j.technovation.2005.04.003

Clark, P. (2006). What would a theory of inter-professional education look like? Some suggestions for developing a theoretical framework for teamwork training. Journal of Inter-professional Care, 20, 577589. http://dx.doi.org/10.1080/13561820600916717

Chickering, W. A., \& Gamson, F. Z. (1987). Seven principles for good practice in undergraduate education. The American Association for Higher Education (AAHE) Bulletin.

Cotton, K. (2000). The schooling practices that matter most (pp. 1-43). Alexandria, VA: Association.

Davis, B. (1993). Tools for teaching. San Fransico, CA: John Wiley \& sons, Inc.

Dewey, J. (1967). Philosophy, psychology and social practice. Capricorn Books.

Epstein, R. (1999). Mindful practice. JAMA, 282, 833-839. http://dx.doi.org/10.1001/jama.282.9.833

Freire, P. (1973). Education for critical consciousness (Vol. 1): Continuum. New York: Seabury.

Freire, P. (1972). Pedagogy of the oppressed. Harmondsworth: Penguin.

Giles, W. (2010). Teacher education in a remote community: Learning on the job. Asian-Pacific Journal of cooperative education, 11, 5765.

Gulino, C. K. (1982). Entering the mysterious dimension of other: An existential approach to nursing care. Nursing Outlook, 30, 1976-
1980.

Gupta, A. (2008). Constructivism and peer coollaboration in elementary mathematics education: Connection to epistemology. Eurasia Journal of Methametics, Science and Technology Education, 4, 381-386.

HSSP. 2005/06-2009/10n and 2010/11-2015/16 Sector Strategic Plan. Kampala: Ministry of Health.

Houston, M., McCune, V., \& Osborne, M. (2011). Flexible learning and its contribution to widening participation: A synthesis of research. Project Report, Higher Education Academy.

Jelesiewicz, E. (2011). Teaching the health sciences: Patients, practice and professionalism.http://eryn.jelesiewicz@temple.edu

Joseph, D. (1985). Humanism as philosophy for nursing. Nursing Forum, 22, 135-138. http://dx.doi.org/10.1111/j.1744-6198.1985.tb00785.x

Kaufmane, M. D. (2003). ABC of learning and teaching in medicine: Applied educational theory in practice. BMJ, 326, 213-216.

Kim Cheng Low Patrick (2011). Must we unlearn to learn well? Educational Research, 2, 1801-1809. http://www.interesjournals.org/ER

Kneller, G. F. (1971). Introduction to philosophy of education. New York: John Wiley.

Kolb. D. A., \& Fry, R. (1975). Towards an applied theory of experiential learning. In C. Cooper (Ed.), Theories of Group Process. London: John Wiley.

Kuh D. G. (2008). High-impact educational practice. What they are, who has access to them, and why they matter. High-Impact Educational Practices, AAC\&U.

Lovat, T. J., \& Smith, D. L. (2003). Curriculum: Action and reflection revised. Wentworth Falls: Social Science Press.

Miettinen, R. (2000). The concept of experiential learning and John Dewey's theory of reflective though and action. International Journal of Lifelong Education, 19, 54-72. http://dx.doi.org/10.1080/026013700293458

Morgan-Klein, B., \& Osborne, M. (2007). The concepts and practice of lifelong learning. London: Routledge

Ministry of Education and Sports (1998). Mulago Paramedical Schools Core Curriculum. Kampala: Ministry of Education and Sports.

Mugisha, W., \& Mugimu, C. (2012). The epistemological aspects of curriculum development and implementation for the medical laboratory technology diploma in Uganda. Creative Education, 3, 281-289. http://dx.doi.org/10.4236/ce.2012.33044

Mugisha, R. W. (2011) Evaluation of practices applied in the curriculum design and implementation of the medical laboratory technology diploma program in Uganda. $\mathrm{PhD}$ Thesis, Kampala: Makerere University.

Piaget, J. (1936). Origins of intelligence in the child. London: Routledge \& Kegan Paul.

Piaget, J. (1957). Construction of reality in the child. London: Routledge \& Kegan Paul.

Percy, K., \& Ramsden, P. (1980). Independent study, two examples from English higher education (pp. 1-9). Surrey: The Society for Research into Higher Education,

PEAP. (2005). Poverty Eradication Action Plan. Kampala: Ministry of Finance, Planning and economic development MOFP\&ED.

Makerere University (2006). Curriculum of Diploma in Medical Laboratory Sciences. Kampala: MLTP Curriculum, Makerere University.

Ministry of Health (2002). Guidelines for Private Practice for Allied Health Professionals and Registered Nurses. Kampala: Ministry of Health.

Rogers, C. R. (1983). Freedom to Learn for the 80s. Columbus, OH: Charles E. Merrill Publishing Company.

Saleh, A. M., Al-Tawil, N. G., \& Al-Hadithi, T. S. (2013). Didactic lectures and interactive sessions in small groups: A comparative study among undergraduate students in Hawler College of medicine. British Journal of Education, Society \& Behavioral Science, 3, 144-153.

Sankey, K., \& Osborne, M. (2006). Lifelong learning reaching regions where other learning doesn't reach. In R. Edwards et al. (Eds.), Researching experiential and community-based learning. London: Routledge.

Sartre, J. P. (1973). Existentialism and humanism. London: Mathuen.

Slavin, E. R. (1996). Research on cooperative learning and achievement: 
What we know. What we need to know. Contemporary Education Psychology, 21, 43-69. http://dx.doi.org/10.1006/ceps.1996.0004

Sullivan, F. R. (2011). Serious and playful inquiry: Epistemologicval aspects of collaborative creativity. Educational Technology \& Society, 14, 55-65.

Suryadi, D., \& Kudwadi, B. (2010). Application of evaluation model counternance in the secondary education curriculum and vocational technology. Proceedings of the 1st UPI International Conference on Technical and Vocational Education and Training, Bandung.

Ministry of Health (1996). The Allied Health Professional's Statute. Kampala: Ministry of Health.

Ministry of Health Uganda. (1999). The Health Policy. Kampala: Ministry of Health Uganda.

Ministry of Health (MOH) Government of Uganda (2000). The Minimum Health Care Package. Kampala: Ministry of Health (MOH) Government of Uganda.
Ministry of Finance, Planning and Economic Development (2003). The Uganda Higher Education Cost. Kampala: Ministry of Finance, Planning and Economic Development.

Triostonstains, R. (1971). Existentialism and Christian thought. Ann Arbor: University Microfilms.

Ministry of Education and Sports (2004). Uganda Higher Education Policy. Kampala: Ministry of Education and Sports.

Vidakovic, D., \& Martin, W. O. (2004). Small group researches for mathematics proofs and individual reconstructions of mathematics concepts. Journal Mathematics Behaviour, 23, 465-492.

http://dx.doi.org/10.1016/j.jmathb.2004.09.006

Vidakovic, D. (1997). Learning of the concept of inverse function in a group versus individual environment. In E. Dubinsky, D. Mathews, \& B. Reymonds (Eds.), Readings in cooperative learning (pp. 175196). MAA Notes No. 44. 